\title{
Rib fixation with a plate for radius and overlapping technique in comminuted fractures
}

\author{
Seok Joo, Yang Bin Jeon \\ Department of Trauma Surgery, Gil Medical Center, Gachon University College of Medicine, Incheon, Republic of Korea
}

A 49-year-old male with sustained multiple comminuted right rib $\left(3^{\text {rd }}-9^{\text {th }}\right)$ fractures, right pneumothorax, and a flail chest was referred with complaints of severe pain. The successful management of the comminuted fractures with a typically used method was deemed not plausible. Therefore, rib fixation was performed using an overlapping technique and plates employed for radius fixation.

Key Words: Rib; Fracture fixation; Orthopedic fixation devices; Flail chest

(Trauma Image Proced 2018(1):28-29)

\section{CASE}

A 49-year-old male with sustained multiple comminuted right rib $\left(3^{\text {rd }-9^{\text {th }}}\right)$ fractures, right pneumothorax, and a flail chest was referred to our hospital with complaints of severe pain. He previously underwent closed thoracostomy in the right thoracic cavity. Rib fixation was performed after 4 days. On evaluation, comminuted fractures of the $4-8^{\text {th }}$ right ribs were detected. We followed a conventional method of using an 8- or 6-hole-plate (MatrixRIB ${ }^{\mathrm{m}}$; DepuySynthes, USA) and an 8- or 4-hole-plate (RibFix $\mathrm{Blu}^{\mathrm{TM}}$; DepuySynthes) for his rib fixation. The fourth rib was fixed using an 8-hole-plate (MatrixRIB ${ }^{\mathrm{m}}$ ). However, the distance of the intact portion on the $5^{-7^{\text {th }}}$ ribs was too long to be successfully managed using a conventionally used plate. Therefore, 8-hole-plates (Small Fragment Locking Compression Plate; DepuySynthes), which are usually employed for radius fixation, were used on these ribs. The $8^{\text {th }}$ rib was fixed with an overlapping method with two flexible 4-hole-plates (RibFix $\mathrm{Blu}^{\mathrm{TM}}$ ) and a longer screw, considering the anatomy of the comminuted fractures (Fig. 1.). The patient was extubated the day after the operation and was transferred to the general ward on the second day after the operation. The plates were intact even on 40th postoperative day.

\section{DISCUSSION}

Surgical management of patients with rib fractures contributes to significant reductions in pneumonia, the length of hospital stay, and intensive care $(1,2)$. Extremely anterior fractures typically cannot be repaired without using costal cartilage as the fixation point. The long-term outcome of costal fixation is unknown. The adequate length for reduction and fixation is typically $3^{-}$

Received: November 5, 2017 Revised: January 2, 2018 Accepted: May 17, 2018

Correspondence to: Yang Bin Jeon, Department of Trauma Surgery, Gil Medical Center, Gachon University College of Medicine, Incheon, Republic of Korea, 21, Namdon-daero, 774 Beon-gil, Namdong-gu, Incheon 21565, Republic of Korea

Tel: 82-32-460-3010, Fax: 82-32-3461-2372, E-mail: junyb@gilhospital.com

Copyright (c) 2018 Korean Association for Research, Procedures and Education on Trauma. All rights reserved.

(c) This is an open-access article distributed under the terms of the Creative Commons Attribution Non-Commercial License (http://creativecommons.org/ licenses/by-nc/4.0) which permits unrestricted noncommercial use, distribution, and reproduction in any medium, provided the original work is properly cited 


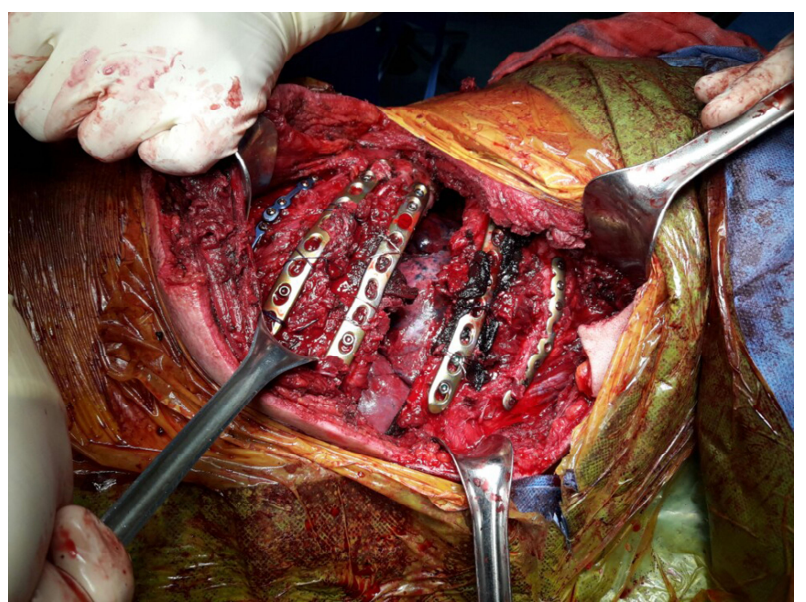

Fig. 1. The fourth rib was fixed using an 8-hole-plate (MatrixRIB ${ }^{\mathrm{TM}}$ ). The ${ }^{-7^{\text {th }}}$ ribs were fixed using 8 -hole-plates (Small Fragment Locking Compression Plate, DepuySynthes, USA). The $8^{\text {th }}$ rib was fixed using two flexible 4-hole-plates (RibFix Blu' ${ }^{\mathrm{TM}}$ )

$5 \mathrm{~cm}$ on either side of the fracture (2). Thus, it is a common practice to typically perform fixation using at least $\geq 2$ screws (usually 3 ) on either side of the fracture for achieving an adequate length for reduction and fixation. Here, the comminuted rib fractures were fixed using the plate for radius and overlapping technique. Thus, a favorable outcome could be anticipated.

\section{Conflict of Interest Statement}

No potential conflict of interest relevant to this article was reported.

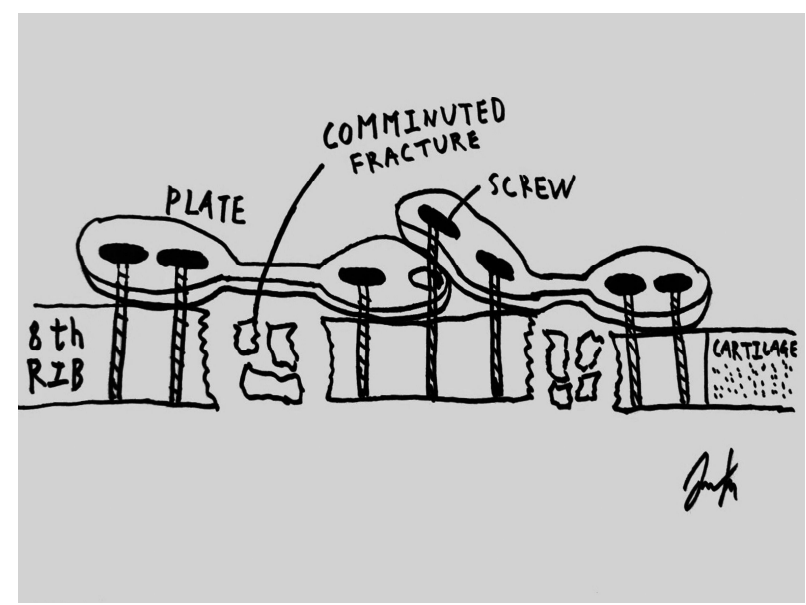

Fig. 2. Details of the fixation of the $8^{\text {th }}$ rib

\section{REFERENCES}

1. Bemelman M, de Kruijf MW, van Baal M, Leenen L., Rib Fractures: To Fix or Not to Fix? An Evidence-Based Algorithm. Korean J Thorac Cardiovasc Surg. 2017;50(4): 229-234

2. Pieracci FM, Rodil M, Stovall RT, Johnson JL, Biffl WL, Mauffrey C, Moore EE, Jurkovich GJ. Surgical stabilization of severe rib fractures. J Trauma Acute Care Surg. 2015; 78(4):883-7 